\title{
Fifty years of Neotropical Entomology
}

\author{
Eliana Maria Gouveia Fontes ${ }^{1} \cdot$ Raul Alberto Laumann $^{1} \cdot$ Daniell Rodrigo Rodrigues Fernandes $^{2}$. \\ Antônio Ricardo Panizzi ${ }^{3}$
}

Accepted: 23 December 2020 / Published online: 11 February 2021

(C) Sociedade Entomológica do Brasil 2021

In 2021 we celebrate the 50th anniversary of Neotropical Entomology journal, formerly known as Anais da Sociedade Entomológica do Brasil (ASEB). Since the publication of the first issue in 1972, the scope of ASEB has been the dissemination of original research in entomology generated, in particular, in Brazil. Later, it expanded greatly to the Neotropics as the journal became more widely known. As we analyze the history of this journal, we become aware of the many difficulties in having it published continuously over time. The success should be credited in particular to the effort and dedication of the Editors, the Editorial Board, and the Board of Directors of the Sociedade Entomológica do Brasil (SEB).

Since its creation, the journal has had a team of high-level editors-in-chief, who have always valued the quality of the articles presented. During the ASEB years, the journal was headed by Carlos Holger Wenzel Flechtmann (who edited the first article in 1972), João Manuel de Abreu and Jorge Octavio Moreno (1972), Luiz Carlos Cruz and João Manuel de Abreu (1973-1974), Fernando Mesquita Lara (19751977), Jocélia Grazia (1978-1984), Luis Amilton Foerster (1984-1990), Jocélia Grazia and Ruth Hildebrand Mocellin (1991-1993), Antônio Ricardo Panizzi and Beatriz Spalding Corrêa-Ferreira (1993-1998), Sueli Souza Martinez (19992004, who led the change of name from ASEB to Neotropical Entomology in 2001), Regina Lúcia Sugayama (2005-2008), Fernando Luis Cônsoli (2008-2016), and Eliana Maria Gouveia Fontes and Raul Alberto Laumann (2016 to the present time). Over the years, ASEB/NENT shows a remarkable increase in quality in editorial terms. It has been a natural evolution, which can be observed in the changes in style and format of the Journal over time (Fig. 1).

Eliana Maria Gouveia Fontes

eliana.fontes@embrapa.br

Embrapa Recursos Genéticos e Biotecnologia, Brasília, DF, Brazil

Instituto Nacional de Pesquisas da Amazônia, Manaus, AM, Brazil

Embrapa Trigo, Passo Fundo, RS, Brazil
Since the early beginnings, the journal has followed the policy of improving its scientific level and quality, with constant concern to be efficient, comprehensive within the entomological knowledge, and with projection to reach the national and international community of entomologists. This editorial is dedicated to all those who contributed to make Neotropical Entomology one of the most respected international scientific journals in entomology. Here we will describe the main steps, since its beginning until the present moment. This process has made it known and appraised, not only locally but also internationally.

Neotropical Entomology began in 1972, the year of creation of the Sociedade Entomológica do Brasil (SEB), with the name Anais da Sociedade Entomológica do Brasil. Over the years, the journal has sustained itself, going through periods of ascension and difficulties in the first two decades. Its goal was to reach the national public, with restricted circulation. The style adopted was that of the Associação Brasileira de Normas Técnicas (ABNT) - today an outdated system — starting with one issue per year. Later, it grew to two, and a few years later, it increased to three issues per year, with irregular frequency and publication time (no fixed month). Several were the obstacles of the first pioneer editors, considering the scarce resources available, in terms of technology and finances.

Twenty-nine issues were published from 1972 to 2000. Many improvements were made to the Journal throughout this period, such as changing the publication only in Portuguese and Spanish, to include the English language, and then to publish only in English, as it is today (Fig. 2). During this period, in the decade of 1990, the journal experienced its first major modifications. These include front cover change, first time printing of text in double columns, inclusion of sections for the different subjects, creation of a Forum section to discuss though-provoking topics, and a substantial upgrade on the editorial board and review system process that much improved the quality and reputation of the journal (Panizzi 1998). By the end of the 1990-decade, Neotropical Entomology was considered a leader among entomology journals in Latin America, attracting entomologist of all countries in the region. 


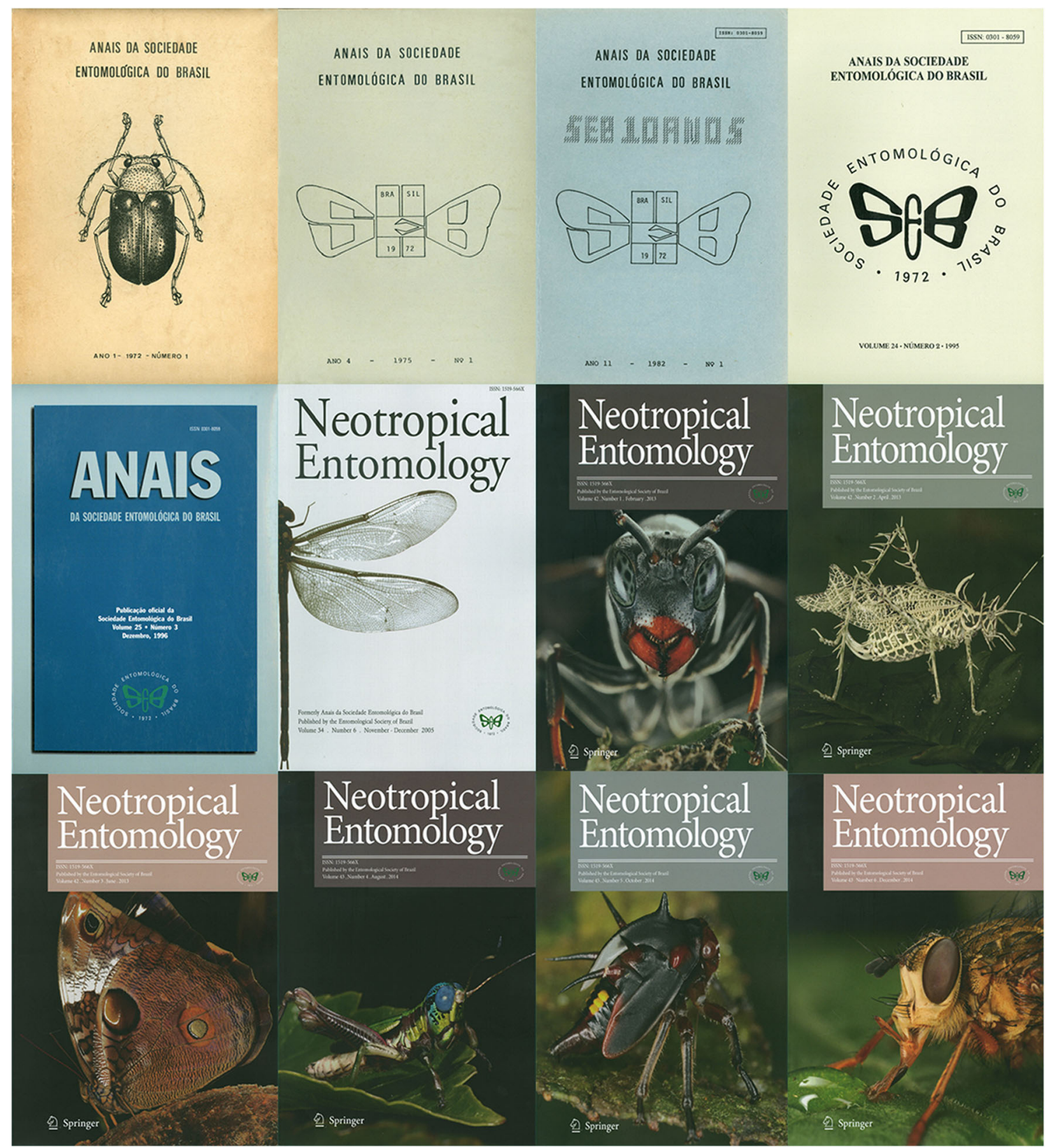

Fig. 1 Different covers published over the years in the ASEB/Neotropical Entomology (from 1972 to 2020)

In 2001, with the arrival of the XXI century, and a new millennium, relevant improvements were made. The journal passed to be called Neotropical Entomology. This increased its visibility and made clear its wider scope. A new format was adopted to adjust to international standards and to increase the number of articles published (Martinez 2001).

To speed up the publication process, a change in periodicity to six issues per year was introduced in 2004, and NENT was inserted in ISI - Science Citation, and Current Contents/ Agriculture, Biology and Environmental Sciences Indexes (currently Web of Science Core Collection) (Martinez 2004). This provided greater visibility and worldwide dissemination of articles and authors. Two years later, in 2006, some layout modifications were implemented, and electronic communication was adopted as the only way to submit articles, through the SciELO platform. This allowed the reduction of production costs and the acceleration of the editorial process (Sugayama 2006).

The most recent and successful change was the establishment of the partnership between Sociedade Entomológica do Brasil and Springer Nature, bringing the production and distribution of Neotropical Entomology to a new era. Issue 1 of volume 41 (2012) was the first to be printed with Springer Nature, taking another step forward to definitively place Neotropical Entomology among the renowned and internationally recognized entomological journals (Cônsoli 2012). 


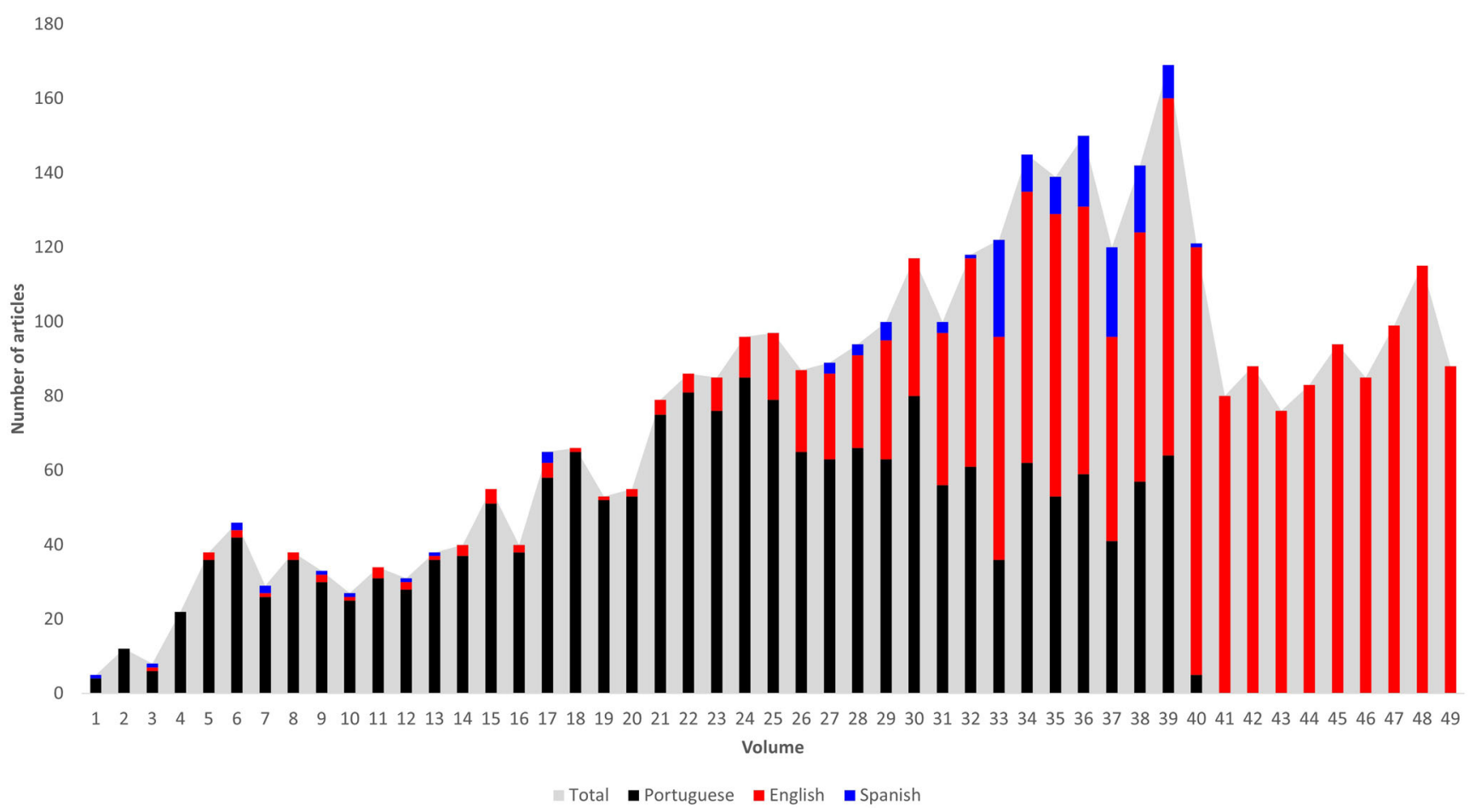

Fig. 2 Yearly evolution on the use of Portuguese, Spanish and English languages in articles published in the ASEB/Neotropical Entomology

A significant increase in the number of articles submitted was registered after inclusion in ISI. Starting with the publication mainly in the field of pest control, today NENT covers a wide range of scientific topics in entomology. The current distribution of articles among the five sections of the journal covers the whole dynamic and diverse scenario of entomological research in the tropical and subtropical areas of the planet (Fig. 3).
As the number of articles received for publication at NENT increased over the years, the need to have another journal was felt. In 2006 the Sociedade Entomológica do Brasil created BioAssay, an electronic journal dedicated to the publication of laboratory and field test results of pest control agents and products (Zucchi 2005; Omoto 2006). More recently, in 2019, meeting the

70

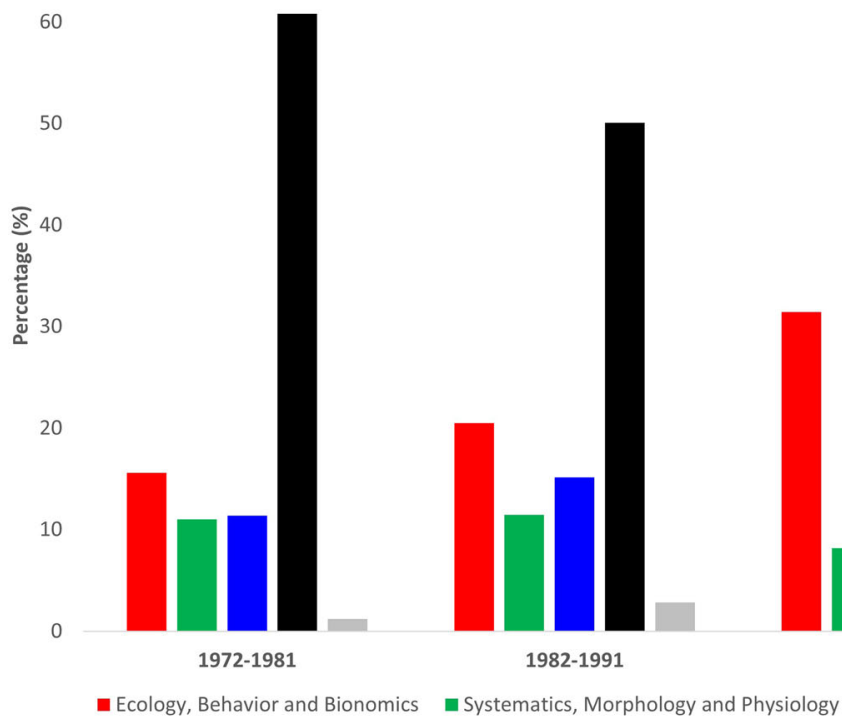

Fig. 3 Distribution of the number of articles among the sections published in ASEB/Neotropical Entomology over the past five decades. It shows an increasing number of articles in the sections Ecology,

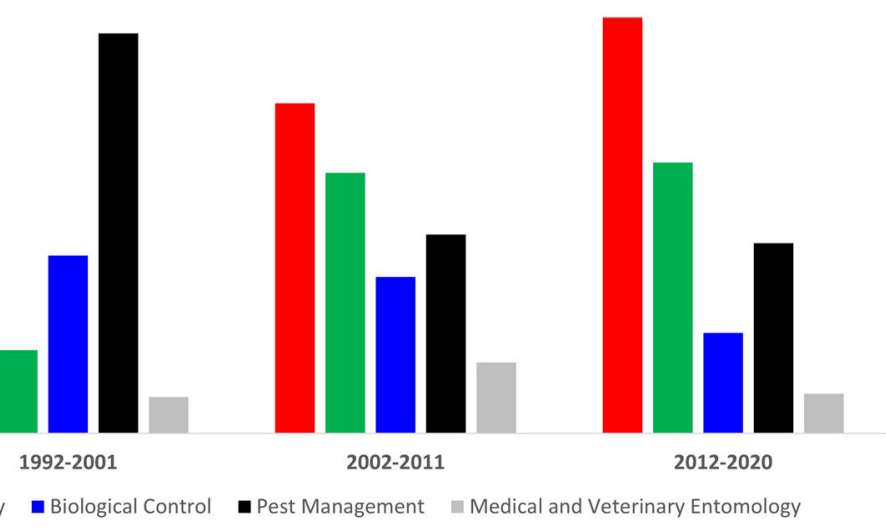

Behavior and Bionomics and Systematics, Morphology and Physiology, and decreasing numbers in the section Pest Management, reveling the broadening of the journal's scope over the years 
demand for a more dynamic communication vehicle of results, SEB created another electronic journal, Entomological Communications, dedicated to the publication of short communications (Fernandes and Pitta 2019).

This 50-year journey of continuous and sustained growth has placed Neotropical Entomology in an excellent position among the entomological journals. The Journal's metric shows an increase of $45 \%$ in the Impact Factor (IF) in the last two years. The IF in 2019 is 1.33 , placing it in the second quartile of entomology (JCR), and Cited Score of 2.1. In 2019 Neotropical Entomology received contributions from authors from 42 countries around the world, and published 64 articles from Latin America, 4 from North America, 8 from Europe, 5 from Asia, and 1 from Africa.

In summary, Neotropical Entomology, in its 50th anniversary in 2021, has a lot to celebrate. From a local journal with restricted circulation within Brazil and few Latin-American countries, today the journal is cosmopolitan. Having its headquarters in the Neotropics, it is located in the core of the most diverse of the zoogeographical regions of the world. This increases its reputation as the journal to disseminate the new discoveries in entomology from this yet little exploited area of the world. It is anticipated that it will rise in importance as a vehicle for the diffusion of knowledge and innovation.

\section{References}

Cônsoli FL (2012) Editorial. Neotrop Entomol 41:1-1. https://doi.org/10. 1007/s13744-012-0022-3

Fernandes DRR, Pitta RM (2019) Entomological Communications. Entomol Commun 1:ec01001. https://doi.org/10.37486/2675-1305. ec01001

Martinez SS (2001) Editorial. Neotrop Entomol 30(1):1-1. https://doi. org/10.1590/S1519-566X2001000100001

Martinez SS (2004) Editorial. Neotrop Entomol 33(1):1-1. https://doi. org/10.1590/S1519-566X2004000100001

Omoto C (2006) Editoria da BioAssay. Informativo da Sociedade Entomológica do Brasil 31(1):2-5

Panizzi AR (1998) Notícias da editoria dos Anais. Informativo da Sociedade Entomológica do Brasil 23(3):2

Sugayama RL (2006) Editorial. Neotrop Entomol 35(1):1-1. https://doi. org/10.1590/S1519-566X2006000100001

Zucchi RA (2005) BioAssay. Informativo da Sociedade Entomológica do Brasil 30(2):2-2 https://seb.org.br/iseb

Publisher's Note Springer Nature remains neutral with regard to jurisdictional claims in published maps and institutional affiliations. 